\title{
Resuscitation of Hypoxic Newborn Piglets With Supplementary Oxygen Induces Dose-Dependent Increase in Matrix Metalloproteinase-Activity and Down-Regulates Vital Genes
}

\author{
RØNNAUG SOLBERG, JANNICKE H. ANDRESEN, SOLVEIG PETTERSEN, MARIANNE S. WRIGHT, BERIT H. MUNKEBY, \\ ELIANE CHARRAT, MICHEL KHRESTCHATISKY, SANTIAGO RIVERA, AND OLA DIDRIK SAUGSTAD
}

\begin{abstract}
Departments of Paediatric Research [R.S., J.H.A., S.P., M.S.W., B.H.M., O.D.S.] and Surgical Research [R.S., J.H.A., B.H.M.], University of Oslo, Oslo University Hospital, Rikshospitalet, N-0027 Oslo, Norway; Neurobiologie des Interactions Cellulaires et Neurophysiopathologie [E.C., M.K., S.R.], UMR 6184 CNRS-Université de la Méditerranée, Faculté de Médecine, 13916 Marseille Cedex 20, France
\end{abstract}

\begin{abstract}
The optimal oxygen concentration for newborn resuscitation is still discussed. Oxygen administration during reoxygenation may induce short- and long-term pathologic changes via oxidative stress and has been associated to later childhood cancer. The aim was to study changes in oxidative stress-associated markers in liver and lung tissue of newborn pigs after acute hypoxia followed by reoxygenation for $30 \mathrm{~min}$ with 21 , 40 , or $100 \%$ oxygen compared with room air or to ventilation with $100 \%$ oxygen without preceding hypoxia. Nine hours after resuscitation, we found a dose-dependent increase in the matrix metalloproteinase gelatinase activity in liver tissue related to percentage oxygen supply by resuscitation $(100 \%$ versus $21 \% ; p=0.002$ ) pointing at more extensive tissue damage. Receiving $100 \%$ oxygen for $30 \mathrm{~min}$ without preceding hypoxia decreased the expression of VEGFR2 and TGFBR3 mRNA in liver tissue, but not in lung tissue. MMP-, VEGF-, and TGF $\beta$-superfamily are vital for the development, growth, and functional integrity of most tissues and our data rise concern about both short- and longterm consequences of even a brief hyperoxic exposure. (Pediatr Res 67: 250-256, 2010)
\end{abstract}

$\mathrm{O}$ ver the last two decades, the traditionally recommended use of $100 \%$ oxygen for newborn resuscitation has been extensively challenged. Meta-analyses have shown room air to be as efficient as $100 \%$ oxygen and that $100 \%$ oxygen increases both mortality and morbidity (1-3). In addition, an association has been found between newborn resuscitation with $100 \%$ oxygen and later childhood cancer $(4,5)$ pointing at the outmost necessity to search for the underlying cause.

Perinatal asphyxia may induce hypoxia-reoxygenation (HR) injury to various organs including liver and lungs, which have important roles in host defense after both organic and inorganic environmental insults (6). Liver-tissue responses to potentially damaging neonatal hypoxia and reoxygenation are of particular interest because of the unique and remarkable capacity of this organ to regenerate after injury via DNA replication and mitosis (7). The lungs are in a direct and

Received May 28, 2009; accepted September 30, 2009.

Correspondence: Rønnaug Solberg, M.D., Department of Paediatric Research, University of Oslo, Oslo University Hospital Rikshospitalet, N-0027 Oslo, Norway; e-mail: ronnaug.solberg@medisin.uio.no

Supported by the South-Eastern Norway Regional Health Authority and the Norwegian SIDS and Stillbirth Society. continuous communication with the outside environment and are exposed directly to the highest partial pressure of inspired $\mathrm{O}_{2}$. The time course of reactive oxygen species (ROS) generation during hypoxia and reperfusion is not clearly understood (8), but experimental evidence indicates a worsening of the hypoxic injury by reoxygenation $(9,10)$. The underlying mechanisms of hypoxia induced liver or lung injury, and the nature of the detrimental biofactors set in motion these circumstances, are still poorly understood. Among the molecules whose expression and activity are modulated in tissue damage and repair are the matrix metalloproteinases (MMPs). MMPs belong to a family of zinc-containing endopeptidases best known for their roles in the physiologic and pathologic remodeling of the extracellular matrix (ECM) during angiogenesis, embryogenesis, wound healing, tumor metastasis, and various cardiovascular and inflammatory diseases (11). MMPs are important in ischemia-reperfusion injury where increased MMP-2 and MMP-9 levels are detected in multiple organs including the brain (12). We and others have recently shown that newborn pigs exposed to hypoxia have increased MMP levels in lung and liver as early as $2-2.5 \mathrm{~h}$ after reoxygenation with $100 \%$ oxygen $(9,13)$. ROS seem to play a role in the cytotoxic activation of some MMPs after ischemia and reoxygenation (14) and may trigger intracellular activation of MMPs where they can mediate early responses to oxidative stress within minutes to hours (15).

Various factors such as vascular endothelial growth factor a (VEGFa) or transforming growth factor $\beta$ (TGF $\beta$ ) stimulate key receptors, VEGF receptor 1 (VEGFR1), VEGF receptor 2 (VEGFR2), and TGF $\beta$ receptor 3 (TGFBR3). They are known to play important roles in angiogenesis and to modulate tissue development and repair from injury, including hypoxia. Interestingly, these factors and their receptors also play key roles in the regulation of MMP expression and activity, and VEGF and MMPs may have a regulatory loop (16). VEGFR2 regulates
Abbreviations: $\mathbf{F i O}_{2}$, fraction of inspired oxygen; MMP, matrix metallopro-
teinase; ROS, reactive oxygen species; TGFBR3, (TGF $\beta$ R3) transforming
growth factor $\beta$ receptor 3; VEGFR1, (Flt-1) vascular endothelial growth
factor receptor 1; VEGFR2, (Flk-1 or KDR) vascular endothelial growth
factor receptor 2 
proliferation and migration of endothelial cells (17) and may play a role in lung tissue remodeling and development of BPD (18). In several tumor forms, there is a loss of TGFBR3 expression that also correlates with a worsening tumor grade (19-21).

Consequently, we wanted to study changes at the molecular and biochemical level in liver and lung tissue after acute hypoxia and reoxygenation with different oxygen concentrations. We sought to investigate these changes at the onset of secondary energy failure and prolonged oxidative stress. For this reason, we extended the observation time from $2.5 \mathrm{~h}$, used previously (9), to $9 \mathrm{~h}$. Moreover, we were also interested in investigating how short exposure to oxygen without preceding hypoxia could influence tissue remodeling and gene regulation.

\section{METHODS}

The Norwegian Council for Animal Research approved the experimental protocol. Animals were cared for and handled in accordance with the European Guidelines for Use of Experimental Animals, by certified FELASA (Federation of European Laboratory Animals Science Association) researchers.

Surgical preparation and anesthesia. Forty-nine newborn Noroc (LY $\times$ LD) pigs, $12-36 \mathrm{~h}$ of age, $\mathrm{Hb}>5 \mathrm{~g} / \mathrm{dL}$, and in good general condition were included in the study. The piglets were anesthetized, orally intubated, ventilated, and surgically prepared as described by Andresen et al. (22).

Experimental protocol. After $60 \mathrm{~min}$ of stabilization, the piglets were randomized to go through global hypoxia and reoxygenation (groups 1-3), to receive $100 \%$ oxygen for $30 \mathrm{~min}$ without preceding hypoxia (group 4), or to be controls (group 0), subjected to the same procedures and observation time but no hypoxia or hyperoxia.

For groups $1-3$, hypoxemia was achieved by ventilation with a gas mixture of $8 \% \mathrm{O}_{2}$ in $\mathrm{N}_{2}$ until either mean arterial blood pressure decreased to $15 \mathrm{~mm}$ $\mathrm{Hg}$ or base excess (BE) reached $-20 \mathrm{mM} / \mathrm{L}$. $\mathrm{CO}_{2}$ was added during hypoxemia aiming at a $\mathrm{PaCO}_{2}$ of $8.0-9.5 \mathrm{kPa}$, to imitate perinatal asphyxia. Before resuscitation, hypoxic piglets were block-randomized into three different groups. Resuscitation was performed for $30 \mathrm{~min}$ with $21 \% \mathrm{O}_{2}$ (group 1), $40 \%$ (group 2), or $100 \% \mathrm{O}_{2}$ (group 3). Thereafter, the piglets were observed for $9 \mathrm{~h}$ [receiving $21 \% \mathrm{O}_{2}$ and normocapnia $\left.\left(\mathrm{PaCO}_{2} 4.5-5.5 \mathrm{kPa}\right)\right]$. At the end of the observation time, the animals were given an overdose of pentobarbital (150 $\mathrm{mg} / \mathrm{kg}$ iv). The liver and lungs were quickly removed, snap frozen in liquid nitrogen, and stored at $-70^{\circ} \mathrm{C}$ until subsequent analysis.

Preparation of liver tissue extracts. Fifty milligrams liver tissue was homogenized in ice-cold lysis buffer [Tris-HC (pH 7.5) with 1\% NP-40 and a protease inhibitor cocktail without EDTA] and MagNA Lyser Green Beads, (Roche Diagnostics GmbH, Mannheim Germany), for $50 \mathrm{~s}$ at $6500 \mathrm{rpm}$, incubated on ice for $15 \mathrm{~min}$ at $4^{\circ} \mathrm{C}$, sonicated for $1 \mathrm{~min}$, and centrifuged at $12000 \times \mathrm{g}\left(4^{\circ} \mathrm{C}\right)$ for $15 \mathrm{~min}$. Supernatants were spun for $5 \mathrm{~min}$, and the protein concentration was measured by BCA method (Pierce, Cheshire, UK).

Gelatin zymography. Ten micrograms of liver tissue protein extract was separated by a SDS-PAGE ( $10 \%$ gel containing $0.1 \%$ gelatin)and assayed for gelatinase activity according to the methods as described elsewhere $(9,23)$. The results were calculated by densitometry, normalized to a representative 21\%, sample of Human MMP-2 and MMP-9 (CC073; Chemicon, Temecula, $\mathrm{CA}$ ), which was used as an internal standard on every zymography run. When the gelatin gel was incubated with $200 \mu \mathrm{M}$ EDTA, no lysis zones were detected, and thus the metal-dependent, lysis-zones were most likely due to MMP activity (gels not shown) (24).

In situ zymography. In situ zymography was performed to localize net gelatinolytic activity in liver and lung sections with minor modifications with respect to a method previously described in brain (12) and lung tissue (9). Because in situ zymography measures many different gelatinases, both liver and lung control slides were incubated with Complete Mini (Roche), a cocktail of EDTA-free nonmetalloproteinase inhibitors and $1 \mathrm{mM} 1.10$ Phenanthroline (Molecular Probes), a broad spectrum metalloproteinase inhibitor. Both inhibitors abolished constitutive and induced gelatinolytic activity in the tissue; thus, the gelatinolytic enzymes are likely to be metalloproteinases. We analyzed three slices per animal. For liver, we used 6-7 piglets per experimental group and for lung 4-5.

The analyses of different hepatic structures were done focusing on the liver lobule, the liver's functional unit with the central vein in the middle and the portal triads at the periphery in the junction to the neighboring lobules. The oxygenation and metabolite supply is best around the portal triad and around the vessels between the lobules and diminishes in parenchyma toward the central vein. We made measurements perivascular, in the triads and in parenchyma.

The analyses of different lung structures were done focusing on areas close to the blood fluid (perivascular) and airways (submucosa) rich on endothelial cells and with higher accessibility toward possible inducing factors like cytokines and ROS than parenchyma.

Tissue preparation for real time PCR. Twenty milligrams of tissue that had been kept in RNASafer were placed in MagNA Lyser Green bead tubes (Roche Diagnostics GmbH, Mannheim, Germany) and TRK lysis buffer. Total RNA from the supernatant was prepared using a Total RNA Kit from E.Z.N.A., and treated with DNase I (E.Z.N.A., Omega Bio-tek). Extracted total RNA was quantified using a ND-1000 spectrophotometer (NanoDrop Technologies). Total RNA (2-3 $\mu \mathrm{g})$ was reverse transcribed into cDNA using the High Capacity cDNA Archive Kit (Applied Biosystems) and incubated in a PTC-100 thermal cycler (MJ Research) according to the manufacturer's protocol. Real-time PCR was performed with $20 \mathrm{ng}$ cDNA for target genes and a housekeeping gene PPIA: peptidylprolyl isomerase A (cyclophilin A) (primers given in Table 1), using the SYBR Green PCR Master mix in an ABI PRISM 7300 Sequence Detection System using universal instrument settings.

$\boldsymbol{R} \boldsymbol{T}$-PCR . Relative expression was determined by the comparative $\mathrm{C}_{\mathrm{T}}$ method of relative quantification (RQ), calculated with the arithmetic formula $2^{-\Delta \mathrm{Ct}}$, where $\Delta \mathrm{Ct}$ is the normalized signal level in a sample $(\Delta \mathrm{Ct}=\mathrm{Ct}$ of target gene - Ct of endogenous control gene) (25).

Real-time quantitative RT-PCR was performed on samples from group 0 (controls), $n=5$; group 1, $n=10$; group 2, $n=12$; group $3, n=10$; and group $4, n=11$.

Statistics. Statistical calculations were performed using SPSS 15.0 statistical package for windows (Chicago, IL). Values are expressed as mean \pm SD. One-way ANOVA with Tukey's post hoc test was used to examine differences between groups. The nonparametric Kruskal-Wallis test was used for the gel zymography results. The relationship between variables was studied using Pearson product-moment correlation coefficient. Statistical difference was accepted at $p<0.05$.

Table 1. Primer concentrations used for RT-PCR

\begin{tabular}{|c|c|c|}
\hline Gene & Forward primer & Reverse primer \\
\hline \multicolumn{3}{|l|}{ MMP-2 } \\
\hline NM_214192 & 5-GGCTTGTCACGTGGTGTCACT-3' & 5'-ATCCGCGGCGAGATCTTCT \\
\hline \multicolumn{3}{|c|}{ 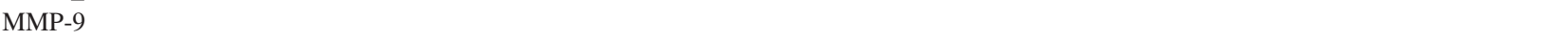 } \\
\hline NM_001038004 & 5'-GAAGCTTTAGAGCCGGTTCCA-3' & 5'-GGCAGCTGGCAGAGGAATATC-3' \\
\hline \multicolumn{3}{|l|}{ VEGFa } \\
\hline NM_214084.1 & 5'-ACGAAGTGGTGAAGTTCATGGA-3' & 5'-CACCAGGGTCTCGATTGGA-3' \\
\hline \multicolumn{3}{|c|}{ 201 } \\
\hline AJ245445 & 5'-CACCCCGGAAATCTATCAGATC-3' & 5'-GAGTACGTGAAGCCGCTGTTG-3' \\
\hline \multicolumn{3}{|l|}{ VEGFR2 } \\
\hline AF233076 & 5'-G ATGCTCGCCTCCCTTTGA-3' & 5'-AGTTCCTTCTTTCAGTCGCCTACA-3' \\
\hline \multicolumn{3}{|l|}{ TGFBR3 } \\
\hline NM_214272.1 & 5'-AAA ATC CGT CAA CTG GGT GAT C-3' & $5^{\prime}$-TTG GGA GCG AGA ACT TTC AGA-3' \\
\hline \multicolumn{3}{|c|}{ PPIA Housekeeping gene } \\
\hline MN_214353 & 5ÀTACGGGTCCTGGCATCTTG (sense) & 5ÀACTGGGAACCGTTTGTGTTG (antisense) \\
\hline
\end{tabular}




\section{RESULTS}

There were no significant differences between the groups with respect to $\mathrm{Hb}$, body weight, age, gender, and for group 1-3 in respect to time of hypoxia. Also $\mathrm{pH}, \mathrm{BE}$, and MABP were not significantly different between the comparable groups (Table 2).

By in situ zymography, we found, for group 1-3, a dosedependent and linear increase in the net gelatinase activity in liver tissue with fraction of inspired oxygen $\left(\mathrm{FiO}_{2}\right)$, (Figs. 1 and $2 A$ ). The highest activity was found in the perivascular and in the triade compartments (Table 2). There was a high correlation between all three areas; vessel versus triade and vessel versus parenchyma $(r=0.7, p=0.001)$. In lung tissue, there was a tendency to a dose-dependent increase in the metalloproteinase activity with $\mathrm{FiO}_{2}$, most prominent in the submucosa and vessel area, (Figs. $2 B$ and 3; Table 3). Resuscitation with $100 \% \mathrm{O}_{2}$ induced significant higher values in the submucosa and vessel area than in the hyperoxia controls who received $100 \% \mathrm{O}_{2}$ without preceding hypoxia. There was a very high correlation between all three areas; submucosa versus vessel and submucosa versus alveoli $(r=0.9, p<$ 0.001).

Gel zymography revealed that the MMPs present in liver tissue were mainly ProMMP-9 and to some extent ProMMP-2 (Fig. 4). There was a positive correlation between ProMMP-2 and ProMMP-9 $(r=0.5, p=0.001)$ but no significant difference within the groups.

Gene expression. In liver tissue, real-time quantitative RTPCR revealed that $100 \%$ oxygen treatment for $30 \mathrm{~min}$ led to a significant down-regulation of VEGFR2 (41\%) and TGFBR3 (37\%) $9 \mathrm{~h}$ after the hyperoxic event, compared with the control group. For TGFBR3, there was also a downregulation in the $40 \%$ and $100 \%$ groups versus the control group (Fig. 5). The expression of VEGFa, VEGFR1, MMP-2,
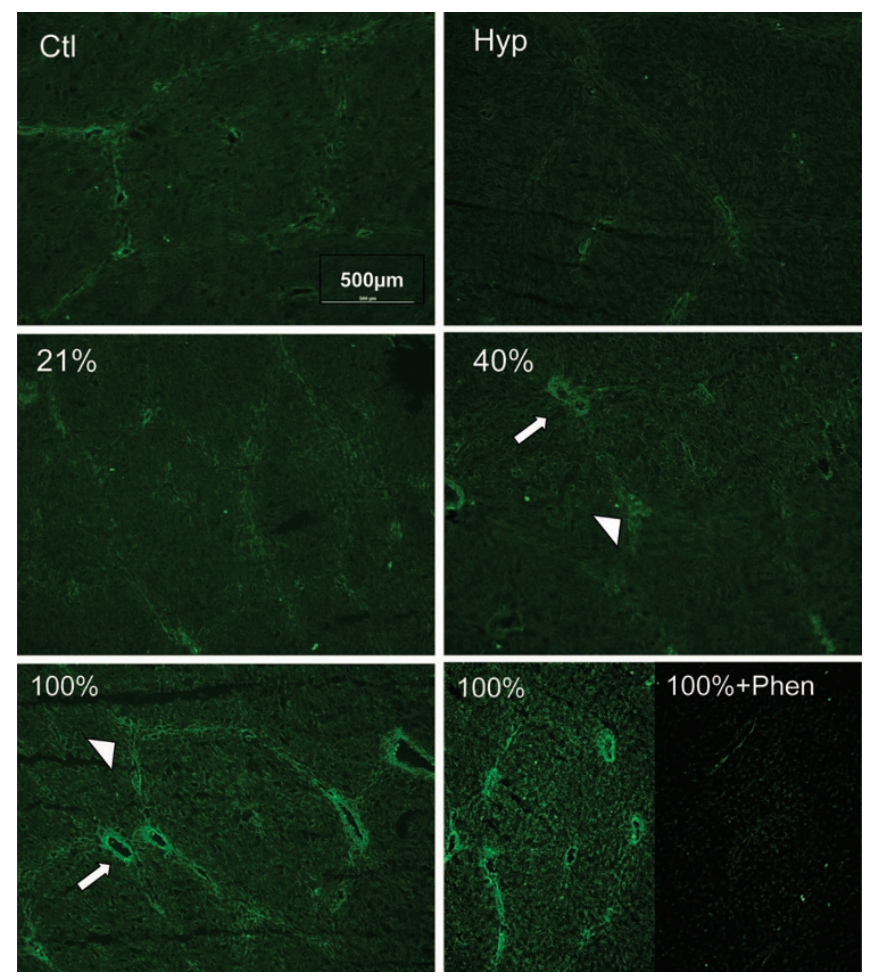

Figure 1. In situ zymography in liver tissue. Fluorescence signals representing proteolytic activity (green) increases in liver sections after hypoxia and subsequent resuscitation. The activity is highest in the perivascular (arrow) and the triade area (arrowhead) and increases proportionally to \% oxygen used for resuscitation. Broad spectrum MMP inhibitor phenanthroline (Phen) nearly abolished gelatinolytic activity. Scale bar: $500 \mu \mathrm{m}$.

and MMP-9 showed no statistical significance within the five groups (data not shown), but RT-PCR $9 \mathrm{~h}$ after reoxygenation revealed a tendency to decreased MMP-9 expression with increasing $\mathrm{FiO}_{2}$. There was a positive correlation between the

Table 2. Background data

\begin{tabular}{|c|c|c|c|c|c|}
\hline & Control & Hyperoxia & $21 \%$ & $40 \%$ & $100 \%$ \\
\hline Weight (g) & $1858(130)$ & $1870(143)$ & $1873(108)$ & $1842(108)$ & $1852(117)$ \\
\hline Age (h) & $35.5(1)$ & $35.1(2.8)$ & $35.1(2.1)$ & $32.8(4)$ & $32.8(5.8)$ \\
\hline Gender M/F & $3 / 3$ & $5 / 6$ & $5 / 5$ & $6 / 6$ & $5 / 5$ \\
\hline $\mathrm{Hb} \mathrm{g} / 100 \mathrm{~mL}$ start & $7.2(0.8)$ & $7.3(1.5)$ & $7.1(0.9)$ & $6.9(1.3)$ & $6.9(1)$ \\
\hline Hypoxia (min) & 0 & 0 & $33.7(8.4)$ & $37.8(15.3)$ & $42.3(15.2)$ \\
\hline $\mathrm{pH}$ start & $7.44(0.05)$ & $7.40(0.05)$ & $7.41(0.06)$ & $7.43(0.05)$ & $7.44(0.06)$ \\
\hline End hypoxia & & & $6.91(0.09)$ & $6.91(0.1)$ & $6.94(0.9)$ \\
\hline End resuscitation & & & $7.17(0.09)$ & $7.18(0.06)$ & $7.25(0.11)$ \\
\hline$>2 \mathrm{~h}$ resuscitation & $7.45(0.05)$ & $7.42(0.08)$ & $7.37(0.05)$ & $7.37(0.05)$ & $7.40(0.08)$ \\
\hline$>5 \mathrm{~h}$ & $7.45(0.06)$ & $7.38(0.09)$ & $7.35(0.06)$ & $7.37(0.06)$ & $7.43(0.07)$ \\
\hline$>9 \mathrm{~h}$ & $7.42(0.08)$ & $7.39(0.11)$ & $7.33(0.06)$ & $7.36(0.08)$ & $7.38(0.11)$ \\
\hline $\mathrm{BE} \mathrm{mmol} / \mathrm{L}$ start & $1.1(2.9)$ & $1.5(3.2)$ & $-0.1(3.6)$ & $0.6(5.7)$ & $2.3(5.2)$ \\
\hline End hypoxia & & & $-19.7(4.2)$ & $-20(3.7)$ & $-18.5(4.7)$ \\
\hline End resuscitation & & & $-14.7(4.5)$ & $-13.9(4.1)$ & $-11.7(5.7)$ \\
\hline$>2 \mathrm{~h}$ & $4.2(4.5)$ & $0.8(6)$ & $-3.5(5.8)$ & $-5.3(3.9)$ & $-2.5(7.7)$ \\
\hline$>5 \mathrm{~h}$ & $1.2(4.9)$ & $-0.6(7.3)$ & $-2.7(5.2)$ & $-4.7(4.5)$ & $-0.1(5.8)$ \\
\hline$>9 \mathrm{~h}$ & $2.1(6.1)$ & $-4.2(7.2)$ & $-6.1(4.8)$ & $-6.3(5.2)$ & $-2.8(7)$ \\
\hline MABP mm Hg start & $43.3(3.4)$ & $42.6(17.3)$ & $49.0(8.4)$ & $47.5(7.8)$ & $51.4(8.3)$ \\
\hline End hypoxia & & & $22.5(15)$ & $22.8(10.8)$ & $22.0(15.5)$ \\
\hline End resuscitation & & & $40.0(15.8)$ & $41.6(12.1)$ & $40.0(11.7)$ \\
\hline$>2 \mathrm{~h}$ & $42.6(5.1)$ & $44.8(8.5)$ & $41.8(12.2)$ & $36.8(11.7)$ & $40.5(10.3)$ \\
\hline$>5 \mathrm{~h}$ & $45.7(16.4)$ & $39.4(9)$ & $42.8(10)$ & $38.4(10)$ & $44.0(9)$ \\
\hline$>9 \mathrm{~h}$ & $38.1(7.1)$ & $40.1(14.7)$ & $35.2(6.7)$ & $39.0(10)$ & $39.4(14.7)$ \\
\hline
\end{tabular}

Values are presented as mean $( \pm \mathrm{SD})$. 


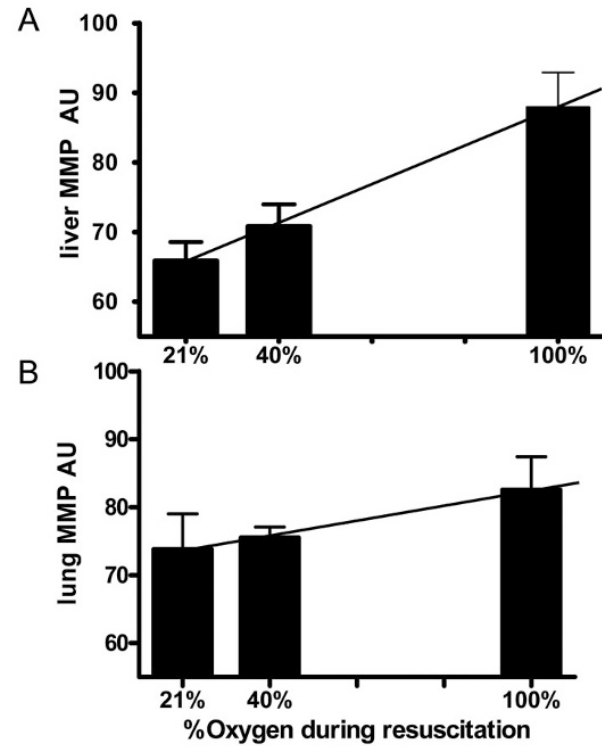

Figure 2. In situ zymography in liver and lung tissue. (A). Quantification of in situ gelatinolytic activity in liver tissue for the hypoxia-reoxygenated groups in arbitrary units (AU) of fluorescence. There is a dose-dependent, significant increase in the net proteolytic activity according to \% oxygen delivered by reoxygenation; $p=0.002$ and $p=0.024$ for $100 \%$ vs $21 \%$ or $40 \%$. (B) Quantification of in situ gelatinolytic activity in lung tissue for the hypoxiareoxygenated groups. There is a dose-dependent and linear increase according to $\%$ oxygen delivered for resuscitation, but NS.

relative expression of VEGFR1 and VEGFa $(r=0.75, p<$ $0.001)$ and VEGFR1 and MMP-9 $(r=0.5, p=0.004)$. In lung tissue, the expression of VEGFa, VEGFR1, VEGFR2, TGFBR3, MMP-2, and MMP-9 showed no significant difference between the five groups (data not shown).

\section{DISCUSSION}

In situ zymography demonstrated that resuscitation of newborn pigs with supplementary oxygen results in a dosedependent increase in the net gelatinase activity in liver and lungs. Gel zymography in liver revealed that the main proportion was ProMMP-9 $(92 \mathrm{kD})$ and to some extent ProMMP-2 (72 kD). We also found a significant downregulation of VEGFR2- and TGFBR3 expression in liver tissue $9 \mathrm{~h}$ after the 30 min exposure to $100 \%$ oxygen versus the otherwise equally treated control group. To our knowledge, our study is the first to point out a decreased expression of these two genes, important for angiogenesis and tumorogenesis, several hours after a relative brief episode of hyperoxia.

MMPs are usually in a balanced state with their natural inhibitors, the tissue inhibitors of MMPs (TIMPs) and the alpha-macroglobulins. ROS and reactive nitrogen species (RNS) are involved in a MMP activation pathway resulting in a conformational change without removal of the propeptide domain (26). They can cause the full length form (72 $\mathrm{kD}$ proMMP-2 and $92 \mathrm{kD}$ proMMP-9) to be proteolytically active (11).

In situ zymography is used to localize gelatinase activity, mainly in relation to expression and activity of MMPs in
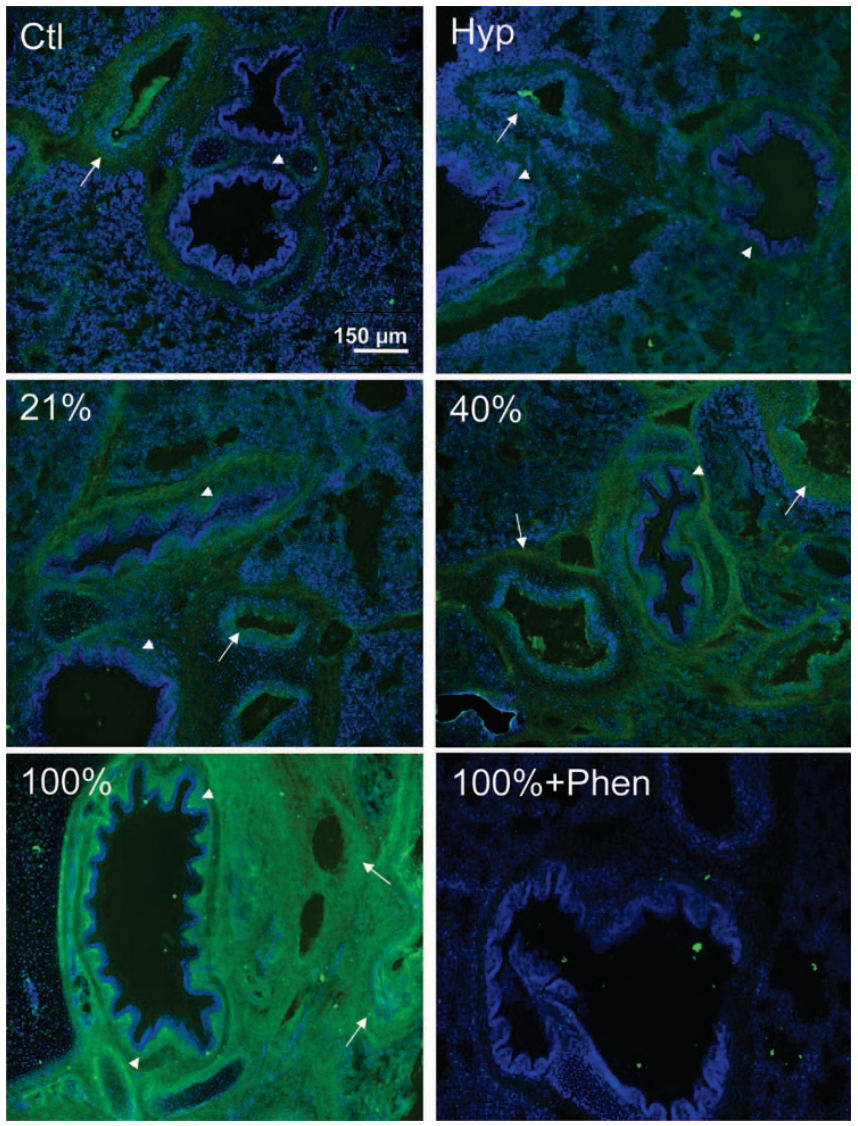

$100 \%+$ Phen

Figure 3. In situ zymography in lung tissue. Net in situ gelatinolytic activity increases in lungs after hypoxia-resuscitation. Fluorescence photomicrographs of lung sections showing in situ zymography in sham operated $(\mathrm{Ctl})$ and hyperoxia (Hyp) controls and after reoxygenation with 21,40 , or $100 \% \mathrm{O}_{2}$. Fluorescence signal representing proteolytic activity (green) shows a tendency to increase after hypoxia-resuscitation in blood vessels (arrows) and submucosa (arrowheads), although only the $100 \%$ group displayed statistically significant differences when compared with the hyperoxia group (see Table 2). Broad spectrum metalloproteinase inhibitor 1,10-phenanthroline (Phen) nearly abolished fluorescence signal, indicating that constitutive and induced gelatinolysis was essentially related to metalloproteinase activity. Hoechst dye was used as a nuclear marker (blue). Images are representative of pictures obtained from five animals per group. Scale bar: $150 \mu \mathrm{m}$.

tissue sections. It reflects the endogenous MMP/TIMP balance in the tissue (12) representative of the net proteolytic activity.

In liver tissue, we found a linear increase in the proteolytic activity for the gelatinases proportional to the oxygen supply by resuscitation. We have in a previous study demonstrated that o-tyrosine, a specific marker of hydroxyl radical attack, is also linear and dose dependently increased after use of supplementary oxygen for resuscitation (27). The highest and significant increased values were measured perivascularly and in the triads, areas with the best oxygenation and metabolite supply.

By in situ zymography, in lung tissue, we found a stepwise increase in the MMP activity proportional to the oxygen supply during reoxygenation. This is most prominent perivascularly and in the submucosa rich in endothelial cells and with a high accessibility toward inducing factors such as cytokines and ROS/RNS. It did not reach statistical significance $p=$ 0.083 (perivascular), $p=0.093$ (submucosa) like in Munkeby's study at $2.5 \mathrm{~h}$ (9) or in liver tissue in this study. One 
Table 3. In situ zymography in liver and lung tissue

\begin{tabular}{|c|c|c|c|c|c|}
\hline & Control & Hyperoxia & $21 \%$ & $40 \%$ & $100 \%$ \\
\hline \multicolumn{6}{|l|}{ Liver } \\
\hline Perivascular & $68.3(10.7)$ & $72.84(8.7)$ & $65.86(7.1)$ & $70.82(8.4)$ & $87.90(13.2)$ \\
\hline Triade & $48.51(6.0)$ & $50.98(7.3)$ & $51.88(4.6)$ & $50.91(6.2)$ & $62.03(11.2)$ \\
\hline Parenchym & $39.14(5.5)$ & $41.57(8.0)$ & $40.95(5.0)$ & $42.40(7.2)$ & $47.58(11.1)$ \\
\hline \multicolumn{6}{|l|}{ Lung } \\
\hline Perivascular & $62.54(11.6)$ & $56.38(13.3)$ & $73.82(11.7)$ & $75.51(3.2)$ & $82.55(9.8)$ \\
\hline Submucosa & $55.55(10.6)$ & $51.44(13.6)$ & $62.17(12.2)$ & $65.89(5.9)$ & $75.01(7.6)$ \\
\hline Alveoli & $53.83(10.6)$ & $50.18(12.2)$ & $53.03(7.5)$ & $60.88(8.2)$ & $66.68(9.6)$ \\
\hline
\end{tabular}

Values are expressed as mean ( $\pm \mathrm{SD}$ ). In perivascular liver tissue, $p=0.002, p=0.024$, and $p=0.011$ for $100 \%$ vs $21 \%$, $40 \%$, and Control group. In liver triade, $p=0.023$ for $100 \%$ vs Control group. In lung tissue, hyperoxia induced significant lower values than resuscitation with $100 \%$ (perivascular $p=0.015$, submucosa $p=0.030$ ) and NS differences between the 21, 40, and 100\% groups (ANOVA with Tukey's post hoc test). In lung tissue, $n=5,5,4,4,5$ and in liver tissue, $n=6,7,7,7,6$ for the Control-, 21\%-, 40\%-, 100\%- and hyperoxia group, respectively.

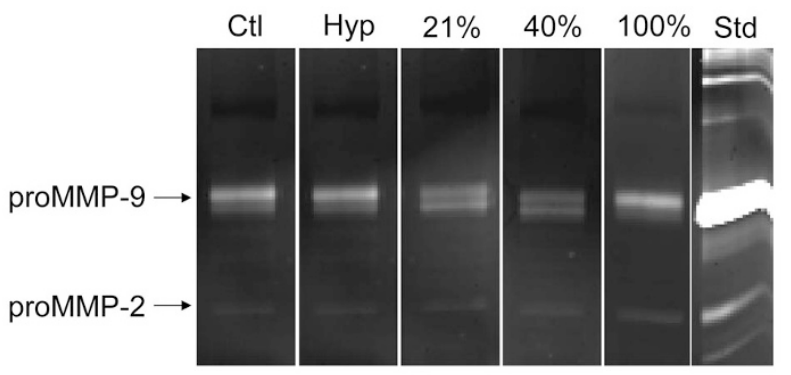

Figure 4. Gel zymograms from liver tissue. Representative zymograms of proMMP-9 and proMMP-2 activities in liver tissue protein extracts in sham operated (Ctl) and hyperoxia (Hyp) controls and after reoxygenation with 21,40 , or $100 \% \mathrm{O}_{2}$. Between the five groups, no significant differences were found. To the right, human MMP-2 and MMP-9 standards were used to determine the bands representing mainly ProMMP-9 and to some extent ProMMP-2.

\section{A}

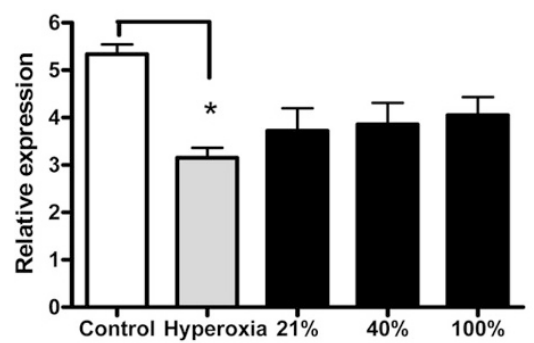

B

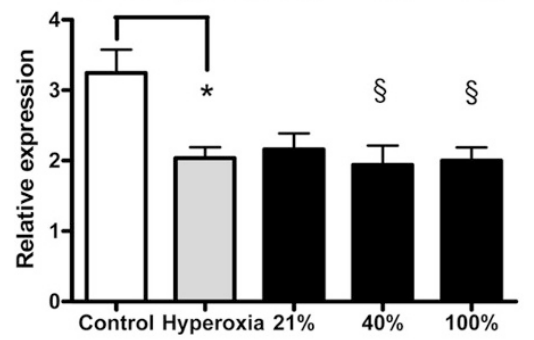

Figure 5. Relative gene expression VEGFR2 and TGFBR3. Relative RNA expression of VEGFR2 $(A)$ and TGFBR3 $(B)$ was determined in liver tissue by quantitative RT-PCR. Both VEGFR2 and TGFBR3 showed a decreased expression in the hyperoxia group $v s$ control $*(p=0.013, p=0.028)$. For TGFBR3, a down-regulation in the $40 \%$ and $100 \%$ groups was also seen $v s$ control $\S(p=0.013, p=0.025)$. Two independent analysis (in duplicates) were done for each individual. Values are expressed as mean $( \pm \mathrm{SD})$. VEGFR2: control 53.4 (4.6), hyperoxia 31.5 (6.9), $21 \% 37.7$ (13.6), $40 \% 38.6$ (15.7), 100\% 40.1 (11.8). TGFBR3: control 32.4 (7.5), hyperoxia 20.4 (5.2), $21 \% 21.6$ (7.2), $40 \% 19.4$ (9.5), $100 \% 20.0(5.2)$. reason could be that a more extensive regular exposure of the lung to high oxygen levels and ROS/RNS could make them more resistant across time. It is likely that changes in the lung occur at early time points, before compensatory mechanisms set in.

A short exposure to $100 \%$ oxygen without preceding hypoxia (group 4) did not result in increased activity and showed significant lower mean values than the group receiving $100 \%$ during resuscitation, indicating that hyperoxia alone is not sufficient to trigger changes at this level, and that the hypoxic event is the factor that sets in motion an imbalance in proteolysis.

Gelatin zymography is a sensitive method to detect the gelatinases MMP-2 and MMP-9 in tissue samples. We found mainly $92 \mathrm{kD}$ MMP-9 and to a lesser extent $72 \mathrm{kD}$ MMP-2, probably due to an earlier up-regulation of MMP-9 after reoxygenation/reperfusion (28) and a stronger 92 kD MMP-9 activation after oxidative stress. The gel zymography did not reveal differences in the expression of MMP-gelatinases within the three groups going through hypoxia and reoxygenation. One reason could be that the liver homogenates reflect the total parenchymal MMP activity, diluting the differences seen in perivascular areas with numerous endothelial cells, but we do not exclude the possibility that other metalloproteinases with gelatinase activity being present in the tissue contribute, at least in part, to net gelatinase activity. Gel zymography reveals the MMPs expression and not the intrinsic activity and is thereby not perfectly comparable to in situ zymography. Oxidative stress may inactivate TIMPs without affecting MMP activity and thereby increase the MMP/TIMP, which would favor net gelatinase activity (29) like we found by in situ zymography.

In this hypoxia-reoxygenation model, we find the same pattern in two organ systems regarding net gelatinase activity as a marker of tissue injury and tissue repair, and the findings support the presumption that ROS and RNS participates in the activation of MMPs at the sites of liver- and lung injury. Increased MMP-9 activity after hyperoxia has been linked to later BPD development (30). There is also an increasing body of research showing that MMPs, and specifically MMP-2 and MMP-9, are involved in tumor growth and metastasis and may have a role in acute lymphoblastic leukemia (ALL) $(31,32)$.

VEGFR2. Exposure to $100 \%$ oxygen for just $30 \mathrm{~min}$ resulted in a $41 \%$ reduction in VEGFR2 mRNA expression 


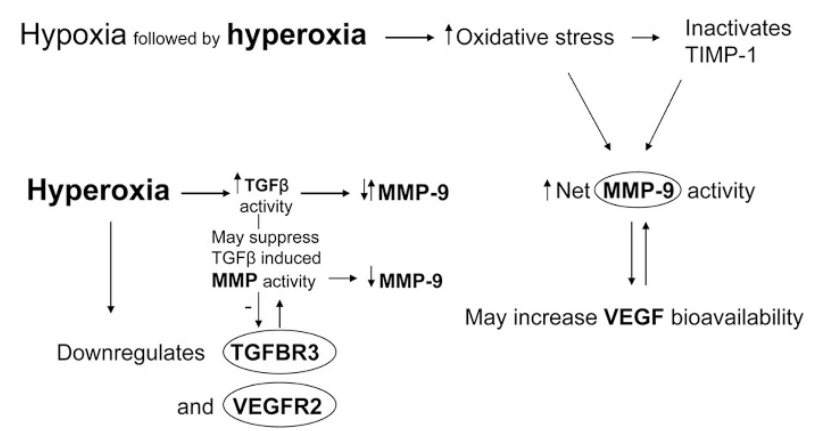

Figure 6. Inter-relationships. There is an extensive interplay between the biofactors studied. MMP-9 function upstream of VEGF/VEGFR2 and may increase the bioavailability of VEGF. Hypoxia followed by hyperoxia increases net proMMP-9 activity. Hyperoxia without preceding hypoxia provoke a decreased expression of VEGFR2 and TGFBR3. TGF $\beta$ may influence the MMP-9 expression and activity and also down-regulate TGFBR3.

measured $9 \mathrm{~h}$ later in liver tissue. This may raise some concerns because VEGFR2 is the major mediator of endothelial cell mitogenesis and survival, as well as of angiogenesis and microvascular permeability (33). A decrease in VEGFR2 expression has been linked to the pathogenesis of hyperoxic lung injury. The very early postnatal period seems to be a critical period for this hyperoxia induced lung injury (18). In mouse liver, VEGFR2 is expressed in the endothelial cells of the sinusoids and portal vein (34), but its role in the liver is unknown. As in the lungs, VEGFR2 could play a role in endothelial cell damage and tissue remodeling.

TGFBR3. A short exposure to $100 \%$ oxygen also reduced the TGFBR3 mRNA expression by $37 \% 9 \mathrm{~h}$ after the hyperoxic event. TGFBR3 seems to have essential roles in cardiovascular and hepatic organogenesis and developmental processes may be disrupted by TGFBR3 deficiency (35). The transforming growth factor $\beta$ (TGF $\beta$ ) family regulates a variety of biologic processes including cell growth, migration, angiogenesis, ECM production, apoptosis, and cancer progression (36,37). Our results could also suggest a potential relevance to recent studies that have revealed that loss of TGFBR3 expression may have important consequences during cancerogenesis (19-21). In addition, also a significantly lower plasma level of TGFBR3 has been found in children with ALL compared with controls (38).

There are complex inter-relationships between the MMP, VEGF, and TGF $\beta$ pathways, a simplified model can be viewed in Fig. 6.

A relatively long period of postnatal maturation in mammals allows for interactions with the environment. Developmental plasticity during critical periods of maturation may result in long-term alterations like blunting of adult hypoxic response after early postnatal hyperoxia exposure, reviewed in Ref. 39. The results of this study, determined in such a critical time window, could contribute to shed light on possible pathologic long-term alterations of this developmental plasticity.

To differentiate between oxygen given for resuscitation and oxygen given without preceding hypoxia seems clinically highly relevant. Still oxygen is used for both newborn resus- citation and stabilization and effects of just a relative short oxygen exposure is important to address.

Limitations. This study has been done in a neonatal, not perinatal, model of hypoxia-reoxygenation. Therefore, caution must be taken when interpreting the current findings in the context of birth asphyxia. Measuring expression and activity at one time-point does not mirror the whole pathophysiological process post hypoxia and reoxygenation. Although the perinatal development of pigs and humans is not identical, it should be emphasized that the pig lung and liver resembles the human not only structurally but also in their immunologic and metabolic functions (40-42).

In conclusion, this study focuses on changes in gene expression and tissue repair mechanisms related to hypoxiareoxygenation and brief oxygen treatment in a newborn model.

The dose-dependent increase that we found in the net gelatinolytic activity (MMP-2 and MMP-9) indicates that using $40 \%$ or $100 \%$ oxygen for newborn resuscitation increases tissue damage and influences remodeling processes. Receiving $100 \%$ oxygen for 30 min without preceding hypoxia provoked a decreased expression of VEGFR2 and TGFBR3 in liver tissue and rises concerns about subsequent impaired angiogenesis and tissue remodeling. We hypothesize that there could be a vulnerable time frame in the neonatal period where a brief exposure to oxygen induces genetic alterations that can lead to long-lasting consequences such as an increased risk of cancer.

Acknowledgments. We thank Cera T. Sebastian, Aurora M. Pamplona, and Roger Ødegård for assistance with the animal preparations; Monica Atnosen-Åsegg, Vibecke M. Olsen, and Iren Helland for technical assistance; and Are Hugo Pripp for biostatistical support.

\section{REFERENCES}

1. Saugstad OD, Ramji S, Soll RF, Vento M 2008 Resuscitation of newborn infants with $21 \%$ or $100 \%$ oxygen: an updated systematic review and meta-analysis. Neonatology 94:176-182

2. Vento M, Sastre J, Asensi MA, Vina J 2005 Room-air resuscitation causes less damage to heart and kidney than $100 \%$ oxygen. Am J Respir Crit Care Med 172:1393-1398

3. Davis PG, Tan A, O'Donnell CP, Schulze A 2004 Resuscitation of newborn infants with $100 \%$ oxygen or air: a systematic review and meta-analysis. Lancet 364:13291333

4. Naumburg E, Bellocco R, Cnattingius S, Jonzon A, Ekbom A 2002 Supplementary oxygen and risk of childhood lymphatic leukaemia. Acta Paediatr 91:1328-1333

5. Spector LG, Klebanoff MA, Feusner JH, Georgieff MK, Ross JA 2005 Childhood cancer following neonatal oxygen supplementation. J Pediatr 147:27-31

6. Greenlee KJ, Werb Z, Kheradmand F 2007 Matrix metalloproteinases in lung: multiple, multifarious, and multifaceted. Physiol Rev 87:69-98

7. Court FG, Wemyss-Holden SA, Dennison AR, Maddern GJ 2002 The mystery of liver regeneration. Br J Surg 89:1089-1095

8. Abramov AY, Scorziello A, Duchen MR 2007 Three distinct mechanisms generate oxygen free radicals in neurons and contribute to cell death during anoxia and reoxygenation. J Neurosci 27:1129-1138

9. Munkeby BH, Borke WB, Bjornland K, Sikkeland LI, Borge GI, Lomo J, Rivera S, Khrestchatisky M, Halvorsen B, Saugstad OD 2005 Resuscitation of hypoxic piglets with $100 \% \mathrm{O}_{2}$ increases pulmonary metalloproteinases and IL-8. Pediatr Res 58:542-548

10. Ben-Yosef Y, Lahat N, Shapiro S, Bitterman H, Miller A 2002 Regulation of endothelial matrix metalloproteinase- 2 by hypoxia/reoxygenation. Circ Res 90:784791

11. Viappiani S, Sariahmetoglu M, Schulz R 2006 The role of matrix metalloproteinase inhibitors in ischemia-reperfusion injury in the liver. Curr Pharm Des 12:2923-2934

12. Rivera S, Ogier C, Jourquin J, Timsit S, Szklarczyk AW, Miller K, Gearing AJ, Kaczmarek L, Khrestchatisky M 2002 Gelatinase B and TIMP-1 are regulated in a 
cell- and time-dependent manner in association with neuronal death and glial reactivity after global forebrain ischemia. Eur J Neurosci 15:19-32

13. Stevens JP, Churchill T, Fokkelman K, Haase E, Idikio H, Korbutt G, Bigam DL, Cheung PY 2008 Oxidative stress and matrix metalloproteinase-9 activity in the liver after hypoxia and reoxygenation with $21 \%$ or $100 \%$ oxygen in newborn piglets. Eur J Pharmacol 580:385-393

14. Gu Z, Kaul M, Yan B, Kridel SJ, Cui J, Strongin A, Smith JW, Liddington RC, Lipton SA 2002 S-nitrosylation of matrix metalloproteinases: signaling pathway to neuronal cell death. Science 297:1186-1190

15. Chow AK, Cena J, Schulz R 2007 Acute actions and novel targets of matrix metalloproteinases in the heart and vasculature. Br J Pharmacol 152:189-205

16. Lee S, Jilani SM, Nikolova GV, Carpizo D, Iruela-Arispe ML 2005 Processing of VEGF-A by matrix metalloproteinases regulates bioavailability and vascular patterning in tumors. J Cell Biol 169:681-691

17. Roy S, Khanna S, Sen CK 2008 Redox regulation of the VEGF signaling path and tissue vascularization: Hydrogen peroxide, the common link between physical exercise and cutaneous wound healing. Free Radic Biol Med 44:180-192

18. McGrath-Morrow SA, Cho C, Cho C, Zhen L, Hicklin DJ, Tuder RM 2005 Vascular endothelial growth factor receptor 2 blockade disrupts postnatal lung development. Am J Respir Cell Mol Biol 32:420-427

19. Finger EC, Turley RS, Dong M, How T, Fields TA, Blobe GC 2008 TbetaRIII suppresses non-small cell lung cancer invasiveness and tumorigenicity. Carcinogenesis 29:528-535

20. Hempel N, How T, Dong M, Murphy SK, Fields TA, Blobe GC 2007 Loss of betaglycan expression in ovarian cancer: role in motility and invasion. Cancer Res 67:5231-5238

21. Dong M, How T, Kirkbride KC, Gordon KJ, Lee JD, Hempel N, Kelly P, Moeller BJ, Marks JR, Blobe GC 2007 The type III TGF-beta receptor suppresses breast cancer progression. J Clin Invest 117:206-217

22. Andresen JH, Carlsen B, Solberg R, Morkrid L, Goverud IL, Loberg EM, Saugstad OD 2009 Newborn piglets exposed to hypoxia after nicotine or saline pretreatment: long-term effects on brain and heart. J Matern Fetal Neonatal Med 22:161-168

23. Kleiner DE, Stetler-Stevenson WG 1994 Quantitative zymography: detection of picogram quantities of gelatinases. Anal Biochem 218:325-329

24. Loy M, Burggraf D, Martens KH, Liebetrau M, Wunderlich N, Bultemeier G, Nemori R, Hamann GF 2002 A gelatin in situ-overlay technique localizes brain matrix metalloproteinase activity in experimental focal cerebral ischemia. J Neurosci Methods 116:125-133

25. Livak KJ, Schmittgen TD 2001 Analysis of relative gene expression data using real-time quantitative PCR and the 2(-Delta Delta C(T)) Method 14. Methods 25:402-408

26. Schulz R 2007 Intracellular targets of matrix metalloproteinase-2 in cardiac disease: rationale and therapeutic approaches. Annu Rev Pharmacol Toxicol 47:211-242

27. Solberg R, Andresen JH, Escrig R, Vento M, Saugstad OD 2007 Resuscitation of hypoxic newborn piglets with oxygen induces a dose-dependent increase in markers of oxidation. Pediatr Res 62:559-563
28. Cursio R, Mari B, Louis K, Rostagno P, Saint-Paul MC, Giudicelli J, Bottero V, Anglard P, Yiotakis A, Dive V, Gugenheim J, Auberger P 2002 Rat liver injury after normothermic ischemia is prevented by a phosphinic matrix metalloproteinase inhibitor. FASEB J 16:93-95

29. Farina AR, Tacconelli A, Cappabianca L, Masciulli MP, Holmgren A, Beckett GJ, Gulino A, Mackay AR 2001 Thioredoxin alters the matrix metalloproteinase/tissue inhibitors of metalloproteinase balance and stimulates human SK-N-SH neuroblastoma cell invasion. Eur J Biochem 268:405-413

30. Tambunting F, Beharry KD, Hartleroad J, Waltzman J, Stavitsky Y, Modanlou HD 2005 Increased lung matrix metalloproteinase-9 levels in extremely premature baboons with bronchopulmonary dysplasia. Pediatr Pulmonol 39:5-14

31. Kuittinen O, Savolainen ER, Koistinen P, Mottonen M, Turpeenniemi-Hujanen T 2001 MMP-2 and MMP-9 expression in adult and childhood acute lymphatic leukemia (ALL). Leuk Res 25:125-131

32. Suminoe A, Matsuzaki A, Hattori H, Koga Y, Ishii E, Hara T 2007 Expression of matrix metalloproteinase (MMP) and tissue inhibitor of MMP (TIMP) genes in blasts of infant acute lymphoblastic leukemia with organ involvement. Leuk Res 31:1437-1440

33. Kung SP, Lee CH, Yang AH, Chi CW, Tseng LM, Wu CW 2006 Expression of c-kit, Flk-1, and Flk-2 receptors in benign and malignant tumors of follicular epithelial origin. J Chin Med Assoc 69:74-79

34. Fujimori H, Asahina K, Shimizu-Saito K, Ikeda R, Tanaka Y, Teramoto K, Morita I, Teraoka H 2008 Vascular endothelial growth factor promotes proliferation and function of hepatocyte-like cells in embryoid bodies formed from mouse embryonic stem cells. J Hepatol 48:962-973

35. Stenvers KL, Tursky ML, Harder KW, Kountouri N, Amatayakul-Chantler S, Grail D, Small C, Weinberg RA, Sizeland AM, Zhu HJ 2003 Heart and liver defects and reduced transforming growth factor beta2 sensitivity in transforming growth factor beta type III receptor-deficient embryos. Mol Cell Biol 23:4371-4385

36. Massague J, Blain SW, Lo RS 2000 TGFbeta signaling in growth control, cancer, and heritable disorders. Cell 103:295-309

37. Ten Dijke P, Goumans MJ, Itoh F, Itoh S 2002 Regulation of cell proliferation by Smad proteins. J Cell Physiol 191:1-16

38. Al-Mowallad A, Carr T, Al-Qouzi A, Li C, Byers R, Kumar S 2006 Plasma CD105, TGFbeta-1, TGFbeta-3 and the ligand/receptor complexes in children with acute lymphoblastic leukaemia. Anticancer Res 26:543-547

39. Bavis RW, Mitchell GS 2008 Long-term effects of the perinatal environment on respiratory control. J Appl Physiol 104:1220-1229

40. Todo G, Herman PG 1986 High-resolution computed tomography of the pig lung. Invest Radiol 21:689-696

41. Gehrke I, Pabst R 1990 Cell composition and lymphocyte subsets in the bronchoalveolar lavage of normal pigs of different ages in comparison with germfree and pneumonic pigs. Lung 168:79-92

42. Swindle MM, Smith AC, Hepburn BJ 1988 Swine as models in experimental surgery. J Invest Surg 1:65-79 